\title{
Environmental anomalies at the World Trade Center: evidence for energetic materials
}

\author{
Kevin R. Ryan · James R. Gourley • \\ Steven E. Jones
}

Published online: 4 August 2008

(C) The Author(s) 2008

\begin{abstract}
Investigators monitoring air quality at the World Trade Center, after the September 11th attacks, found extremely high levels of volatile organic chemicals as well as unusual species that had never been seen before in structure fires. Data collected by the U.S. Environmental Protection Agency indicate striking spikes in levels of benzene, styrene, and several other products of combustion. These spikes occurred on specific dates in October and November 2001, and February 2002. Additionally, data collected by researchers at the University of California Davis showed similar spikes in the levels of sulfur and silicon compounds, and certain metals, in aerosols. To better explain these data, as well as the unusual detection of 1,3-diphenylpropane, the presence of energetic nanocomposites in the pile at Ground Zero is hypothesized.
\end{abstract}

Keywords World Trade Center - EPA .

1,3-diphenylpropane - Aluminothermics .

Energetic nanocomposites - Volatile organic chemicals

\section{Introduction}

For months after the destruction at the World Trade Center (WTC) on 11th September, 2001, the fires at Ground Zero (GZ) could not be put out, despite the following facts.

K. R. Ryan $(\bowtie)$

P.O. Box 53, Bloomington, IN 47402-0053, USA

e-mail: kncryan@msn.com

J. R. Gourley

Dallas, TX 75231, USA

S. E. Jones

S\&J Scientific Co., Provo 84604, UT, USA
- Several inches of dust covered the entire area after the destruction of the WTC buildings.

- Millions of gallons of water were sprayed onto the debris pile.

- Several rainfall events occurred at GZ, some heavy; and

- A chemical fire suppressant called Pyrocool was pumped into the piles (Lipton and Revkin 2001).

The characteristics of these un-extinguishable fires have not been adequately explained as the results of a normal structure fire, even one accelerated by jet fuel. Conversely, such fires are better explained given the presence of chemical energetic materials, which provide their own fuel and oxidant and are not deterred by water, dust, or chemical suppressants.

Apart from the extensive but failed efforts to extinguish the fires, there are several other physical indicators of the presence of energetic chemical reactions in the rubble at GZ. These include the following.

1. Photographs and witness testimony evidencing molten metal and explosions accompanied by white dust clouds (Jones 2006; Meyerowitz 2006; PBS 2002).

2. Extremely high temperatures in the fires at the WTC (Jones et al. 2008a).

3. Unusual spikes in volatile organic chemical (VOC) emissions, suggesting abrupt, violent fires on specific dates.

4. Unusual species in the environmental monitoring data, also corresponding to specific dates.

Explosions followed by white dust clouds, and molten metal at GZ, are of particular interest in this analysis. A white dust cloud is one of the products of the thermite reaction. The white dust in this case is aluminum oxide, 
released from the extremely exothermic reaction between aluminum and iron oxide. The other product of the thermite reaction is molten iron. These facts, coupled with evidence for extremely high temperatures at the WTC, suggest that investigators should examine the potential for such pyrotechnic materials at the WTC. The environmental data described below give more compelling evidence to support such an inquiry.

\section{EPA data on VOC emissions from GZ}

Through a Freedom of Information Act (FOIA) request, access to environmental monitoring data from the U.S. Environmental Protection Agency's (EPA) WTC response was obtained (EPA 2004). The data set shows that spikes in the levels of airborne VOCs occurred on specific dates at GZ (Austin Tobin Plaza, WTC 1 or WTC 2), with levels of the related contaminants rising sharply and then falling dramatically back to baseline levels, usually within 1 day or less. An example is shown in Fig. 1, for detections of benzene.

Benzene is a major product of the combustion of plastics and other organic materials. In a typical structure fire, when plastics are abundant, benzene levels have been seen at levels as high as $26 \mathrm{ppb}$ (MOEE 1997). Apart from fires, benzene is seen in high-traffic areas of urban settings, with mean levels of $\sim 4$ ppb (Crebellia et al. 2001).

Serious health consequences are known to occur when breathing benzene at $100 \mathrm{ppb}$, and it is known to cause diseases such as leukemia (HHS 2007). Note that, for the first few weeks after 9/11, the levels of benzene detected at GZ were relatively low, although perhaps higher than historical levels from structure fires. But the maximum value detected in November 2001 was $180,000 \mathrm{ppb}$, and the average daily detection for October and November 2001 was $18,000 \mathrm{ppb}$. The five peaks in benzene detection occurred on 5th October, 11th October, 3rd November, 8th November, and 16th November.

Similarly, the data for styrene are presented in Fig. 2.

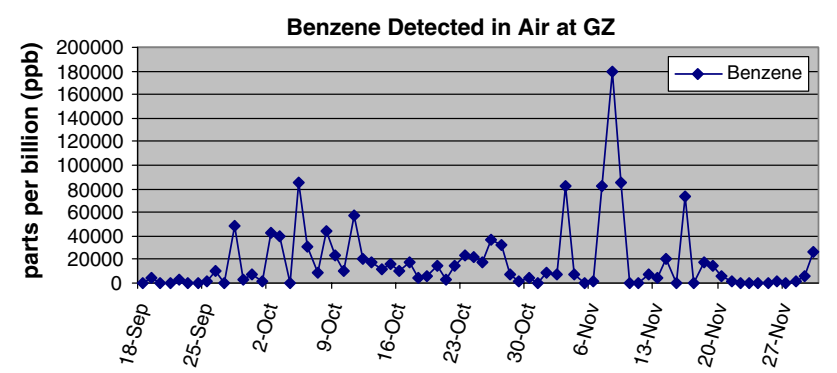

Fig. 1 EPA maximum daily detection of benzene in air at GZ, September through November 2001

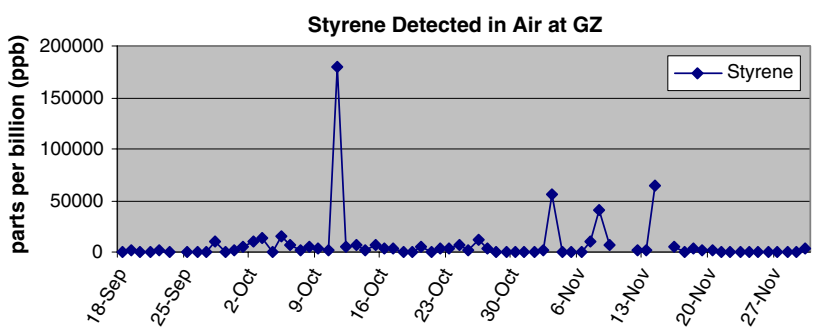

Fig. 2 EPA maximum daily detection of styrene in air at GZ, September through November 2001

The spikes in detected levels of styrene are more prominent. Styrene is normally seen as a product of the combustion of plastics, notably polystyrene. Interestingly, the dates of the five highest levels of styrene detection occurred on the same dates as those of highest detection of benzene.

A similar pattern in detection was noted in the data for several other analytes monitored by EPA in the air above the rubble piles at GZ. For example, toluene, ethylbenzene, and propylene follow the same pattern of spiked detection levels as seen above. These FOIA-obtained data indicate that all five of these VOCs were detected far above the levels published by EPA in their reports for the general public (Fig. 3, EPA 2002).

The occurrence of such extreme, sharp spikes in VOCs in air at GZ indicate something other than the behavior of a typical structure fire. Oxygen influx as a result of shifting of materials within the pile might have created an increase in combustion of material in localized areas. But these spikes in VOCs, at levels thousands of times higher than seen in other structure fires, suggest extremely violent but short-lived fire events.

Probably the most striking spike in toxic air emissions, found in EPA monitoring data, occurred on 9th February, 2002. Note (Table 1 ) that this was nearly 5 months after 9/11, and after nearly all the debris had been cleared from GZ. In fact, the levels of some species, like toluene and styrene, were some of the highest observed at the site. But the levels of benzene and propylene detected on that day were far above previous measurements, at 610,000 and

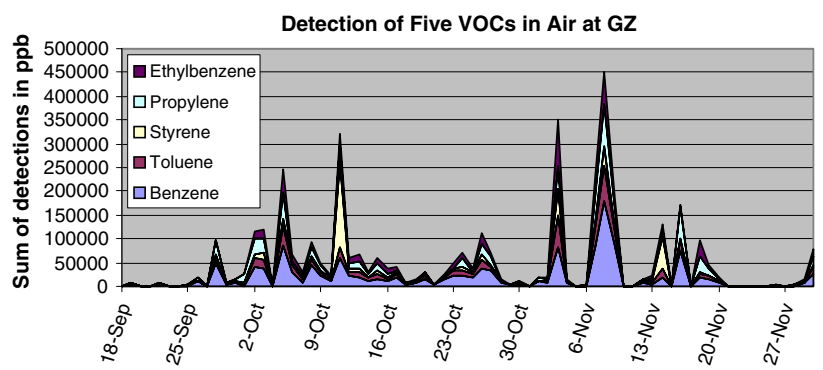

Fig. 3 EPA maximum daily detection of VOCs in air at GZ, September through November 2001 
Table 1 Six dates of maximum detection for five species in air at GZ (ppb)

\begin{tabular}{llclcrr}
\hline Analyte & 5 th October & 11th October & 3rd November & 8th November & 16th November & 9th February \\
\hline Benzene & 86,000 & 58,000 & 83,000 & 180,000 & 73,000 & 610,000 \\
Ethylbenzene & 48,000 & 23,000 & 95,000 & 67,000 & $34,000^{\mathrm{a}}$ & 5,000 \\
Propylene & 56,000 & 37,000 & 49,000 & 92,000 & 66,000 & 23,000 \\
Toluene & 40,000 & 23,000 & 67,000 & 74,000 & 690,000 \\
Styrene & 15,000 & 180,000 & 56,000 & 40,000 & $64,000^{\mathrm{b}}$ & 17,000 \\
\hline
\end{tabular}

${ }^{a}$ Measured on 18th November

b Measured on 14th November

990,000 ppb, respectively. Other VOCs were measured at their peak levels on this date, including 1,3-butadiene at 400,000 ppb.

EPA also monitored very fine particulate matter (PM) and other sizes of PM. PM is probably the most reliable indicator for the activity of structure fires, as such fires are generally known to burn incompletely, and produce PM that drifts up and outward from the source. EPA data from the West Broadway sampling site, the location closest to GZ where PM was monitored, show the following trend in very fine $\mathrm{PM}\left(\mathrm{PM}_{2.5}\right.$, or all particles $\left.<2.5 \mu \mathrm{m}\right)$ in October and November 2001 (Fig. 4).

These data show that the peaks in levels of very fine PM near GZ correspond to different dates than the peaks for the previously discussed combustion products. The five strongest peaks in $\mathrm{PM}_{2.5}$ levels are centered on 23th, 26th September, and 3rd, 10th, 20th October, closer in time to the events of 9/11. None of these dates correspond to the dates of five peaks in VOCs noted above. Additionally, it is clear that the levels of $\mathrm{PM}_{2.5}$ emissions rose more gradually, and died down more gradually, indicating slower fire dynamics as might be expected from the burning of the organic materials previously thought to exist in the WTC.

These data suggest that the greatest level of fire activity, associated solely with the typical fuel sources expected in the WTC, was completed by the third week of October. That is, the materials expected to burn (incompletely) in a structure fire, producing PM, were largely burned off by mid- to late-October.

Therefore, the extreme spikes in air concentrations of the five VOCs noted above, particularly on 3rd, 8th

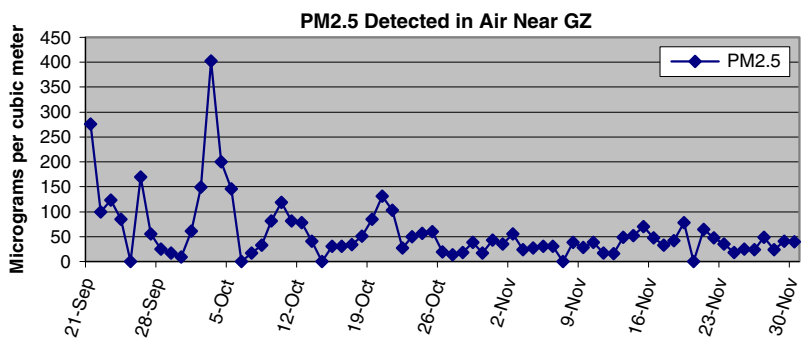

Fig. 4 Very fine PM detected in air by EPA near GZ in late 2001
November, and 9th February, point not to other sources of typical combustible materials but to other forms of combustion. Such forms of combustion appear to be violent and short-lived, and thus similar to the effects of energetic materials, like thermite.

\section{Aerosol measurements after 9/11}

Thomas Cahill, of the University of California Davis, reported similar unusual environmental data collected near GZ, although only through the month of October 2001. Cahill's team monitored for the presence of aerosols at a distance of $\sim 1.8 \mathrm{~km}$ (1.1 mile) from GZ during this time.

The data produced by this team were difficult to explain. For example, with regard to more coarse particles detected in the air at GZ, the following statements were made.

“These particles simply should not be there," Cahill said. "It had rained, sometimes heavily, on six days in the prior three weeks. That rain should have settled these coarse particles." (Wright 2002)

With respect to fine particles, Cahill and his team saw three problems with the data, and explained those basic problems in this manner.

- We see very fine aerosols typical of combustion temperatures far higher than [expected in] the WTC collapse piles.

- We see some elements abundantly and others hardly at all, despite similar abundances in the collapse dust.

- We see organic species in the very fine mode that would not survive high temperatures (Cahill et al. 2003).

According to Cahill, the very fine particles found contained high levels of sulfur and/or sulfur-based compounds, as well as high levels of very fine (chemically bound) silicon. Note that Cahill's team used synchrotron X-ray fluorescence to measure elements in air, and therefore did 
not distinguish between these elements and their compounds.

The silicon compounds were conjectured to originate from thousands of tons of glass in the debris. The metals found by Cahill's team in relatively high concentrations were iron, titanium, vanadium, nickel, copper, and zinc. Although the sources of some of these metals were not described precisely, Cahill suggested that iron and titanium were "associated with powdered concrete," and vanadium and nickel were "often associated with fuel-oil combustion" (Wright 2002).

Interestingly, the Cahill data exhibited similar dramatic peaks in maximum detection related to some elements, particularly silicon compounds. Although the measurements made by this group were reported only for October, the dates 5 th and 11th October stand out as peak maxima for silicon, corresponding to the dates in October of peak detections for benzene, ethylbenzene, propylene, styrene, and toluene. Cahill's team made the following statements about silicon being dominant, and other similar species being absent, in what they called the very fine mode.

Silicon dominates all other elements, unlike the coarse mode aerosols... (Cahill et al. 2004)

other crustal elements ( $\mathrm{Al}, \mathrm{Ca}$, and iron) seen so abundantly in the coarser particles are essentially absent in this very fine mode. (Cahill 2003)

In July of 2002, Cahill reported that (emphasis added)

The air from Ground Zero was laden with extremely high amounts of very small particles, probably associated with high temperatures in the underground debris pile. (ENS 2002)

But by September 2002, Cahill appeared to have changed his mind on the "high temperatures," and attempted to explain some of the unusually high levels of metals in his data by invoking a new mechanism of "anaerobic incineration." Because the existence of high-temperature fires, necessary to volatilize such metals, was not compatible with the common understanding that only typical fuel sources could be involved, it was proposed that chlorine was present at concentrations of $\sim 10 \%$, causing the metals to volatilize at lower temperatures (Cahill et al. 2003; Dalton 2003).

This hypothesis for the volatilization of metals is not well defined. It is clear that $10 \%$ chlorine gas could not be the reactive species in Cahill's hypothesis, but as stated before, it is also clear that Cahill and his team did not distinguish between elemental forms and compounds. Chlorine gas, which is highly reactive, would not form at $10 \%$ in air in such an environment, and if it did it would have been fatal to workers in the area. But chlorinated compounds are generated in structure fires. Perhaps Cahill was proposing a gradient of concentrations for such compounds in air around the pile, with a concentration of $10 \%$ being coincidentally located around the fuel oil source for vanadium and nickel.

The only fuel oil source suggested by Cahill and his team was under WTC building 7, across the street from the towers (Cahill et al. 2004). But it should be noted that government investigators have suggested that the fuel oil in question was burned to create the fires that caused WTC building 7 to collapse. If one assumes they were correct, that fuel oil would no longer be available as the source of vanadium and nickel more than 1 month later.

Additionally, Cahill's hypothesis seems to require a complicated, multi-step process of metal chlorination in the pile and then de-chlorination after oxygen and/or water levels returned, in order to allow for the species measured $1.8 \mathrm{~km}$ away.

The mechanism proposed is then the formation of gasses in the oxygen-poor, chlorine rich collapse piles, emission through the rubble and conversion at or near the surface into oxidized forms and thus very fine particles. (Cahill et al. 2003)

A better explanation for the data collected involves the presence of short-lived, violent fires at GZ. A typical modern day form of thermite, used in military devices for metal cutting, is thermate, with finely powdered sulfur added as part of a flare mixture. Additionally, aluminothermic materials can explain the presence of unusual metals and silica in fine PM, as described below.

\section{The unusual detection of 1,3-diphenylpropane}

Cahill did not have an explanation for the third part of the problem that his team saw. That is, what effect at the WTC would cause organic compounds in very fine aerosols that would not survive high temperatures? Although Cahill did not specifically identify these organic species, EPA did mention one. This analyte detected by EPA may be the most interesting in the environmental data from the WTC: 1,3-diphenylpropane [abbreviated 1,3-DPP with IUPAC name $1^{\prime}, 1^{\prime}$-(1,3-propanediyl)bis-benzene].

EPA's Erik Swartz stated that 1,3-DPP was present at levels "that dwarfed all others." Swartz went on to say"We've never observed it in any sampling we've ever done" (Garrett 2003). An EPA publication on the findings stated:

This species has not previously been reported from ambient sampling. It has been associated with polyvinyl chloride materials, which are believed to be in 
abundance at the WTC site. These emissions lasted for over three weeks (9/26/01-10/20/01) after the initial destruction of the WTC. (EPA 2006)

The fact that this species had never been found before is a startling fact, considering that EPA has monitored extreme structure fires before, including those in which polyvinyl chloride (PVC) materials were present. In fact,

EPA officials and fire-fighting experts were well aware, from previous studies of a handful of spectacular and tragic fires in hotels, commercial buildings and downtown areas, that such blazes are capable of releasing a witch's brew of some of the most toxic substances known-including mercury, benzene, lead, chlorinated hydrocarbons and dioxins. (Gonzalez 2002)

EPA's history with structure fire monitoring indicates that, to have never seen an organic compound like 1,3-DPP is very unusual, especially when it was found at such high levels. But 1,3-DPP was not only at high levels, it was also reported to have been "pervasive" (American Scientist 2003).

Considering how unusual, abundant, and pervasive 1,3DPP was reported to be, it is remarkable that EPA released only five results for this compound, and all of these from only one location - the 290 Broadway site of EPA itself. But even at this one site, its clear that 1,3-DPP was measured at levels that were as much as 30 times greater than typical semi-volatile organic combustion products like naphthalene and biphenyl. Additional details about EPA's measurements of 1,3-DPP will have to wait. Repeated delays in the fulfillment of the FOIA mentioned above, and a response letter indicating EPA will withhold a majority of the related documents, suggest that EPA has more data on 1,3-DPP but is reluctant to release it.

Unlike the EPA publication, Swartz did not attribute the high levels of 1,3-DPP to the combustion of PVC. In fact, there are no readily available references to indicate how 1,3-DPP is "associated with PVC," and the pathway of such degradation via combustion would be complicated, at best.

Instead, Swartz attributed the presence of 1,3-DPP to polystyrene and other plastics, by stating

[1,3-DPP was] primarily found in the gas phase (with $90 \%$ of the mass found on the front denuder). Although the source of the compound in this study is not known, it may have formed during the combustion of polystyrene or other polymers. 1,3-Diphenylpropane has been found to co-occur with polystyrene plastics $(37,38)$, so another possibility is that the compound was already present and encapsulated in large volumes of plastics in the buildings and was off-gassed during the pulverization process. (Swartz et al. 2003)

However, the sources Swartz uses to support 1,3-DPP as a combustion product of polystyrene are not studies of polystyrene combustion, but of gasses released in the longterm degradation of enclosed polystyrene food product packaging.

Other studies have shown trace amounts of 1,3-DPP as a secondary product of polystyrene combustion or thermolysis. But such studies suggest that 1,3-DPP may only form in negligible quantities and under certain conditions (Boettner et al. 1973; McCaffrey et al. 1996). In such experiments, the major product of the combustion or thermolysis of polystyrene, far outweighing others, is the monomer styrene. This leads us to the fact that, although styrene was a species of interest at 290 Broadway during the same time period as was 1,3-DPP, styrene detections were not reported in the FOIA provided data (EPA 2004). Therefore, it appears that Swartz' first suggested hypothesis, that 1,3-DPP resulted from combustion of polystyrene, is not probable.

The possibility that 1,3-DPP was off-gassed as a result of the physical destruction of debris at GZ, as in Swartz' second hypothesis, seems possible. But it is one thing to suggest that 1,3-DPP was "encapsulated in large volumes of plastics in the buildings" and another thing to state in what exact materials this rare compound was encapsulated. Consumer plastics do not typically have large amounts of unusual organic compounds just simply "encapsulated" within them.

A review of the literature uncovers one interesting source of encapsulated 1,3-DPP that may help to explain much of the unusual environmental data described above. The synthesis of novel nanostructured materials has involved the use of 1,3-DPP to functionalize mesoporous silicas through control of pore size (Kidder et al. 2003).

The resulting novel hybrid materials possess silyl aryl ether linkages to the silica surface that are thermally stable to ca. $550^{\circ} \mathrm{C}$, but can be easily cleaved at room temperature with aqueous base for quantitative recovery of the organic moieties. (Kidder et al. 2005)

Such novel nanostructured materials are known to have been the focus of intense research in the past 10 years, particularly with regard to energetic nanocomposites. Energetic nanocomposites are hybrid sol-gel materials, often made with a silica base, that have been combined with metal oxides and nano-scale aluminum powder to form superthermite materials. Much of this work has been done at Lawrence Livermore National Laboratories (Gash et al. 2000; Clapsaddle et al. 2004, 2005; Simpson et al. 2004). 
Similar energetic nanocomposites have been known to be amenable to spray-on applications. In fact, some investigators have reported that

The sol-gel process is very amenable to dip-, spin-, and spray-coating technologies to coat surfaces. We have utilized this property to dip-coat various substrates to make sol-gel $\mathrm{Fe}_{2} \mathrm{O}_{3} / \mathrm{Al} / \mathrm{Viton}$ coatings. The energetic coating dries to give a nice adherent film. Preliminary experiments indicate that films of the hybrid material are self-propagating when ignited by thermal stimulus. (Gash et al. 2002)

Apart from iron oxide, other metallic oxides commonly used as oxidizers in various forms of thermite mixtures include $\mathrm{MoO}_{3}$ and $\mathrm{CuO}$ (Prakash et al. 2004). Although EPA did not test for molybdenum, the data show a dramatic spike in copper detection on 8th October. Note that EPA's analysis of metals in air samples utilized inductively coupled argon plasma, and therefore also did not distinguish between these metals and their compounds.

It is worth noting that the United States Geological Survey (USGS) found and studied one or more molybdenum spheres in the WTC dust (Jones et al. 2008a). This fact gives evidence for the presence of molten molybdenum, and therefore possibly the related, high temperature aluminothermic reaction.

\section{Hypothesis for release of 1,3-DPP and other unusual species at WTC}

If energetic nanocomposites were present at the WTC, the presence of 1,3-DPP might be explained through a mechanism of release from the silica microstructure by aqueous base. As noted above, the silyl aryl ether linkage of the composite is "thermally stable to $\mathrm{ca}$. $550^{\circ} \mathrm{C}$ " but yet, the organic moieties "can be easily cleaved at room temperature with aqueous base for quantitative recovery." The dust at GZ was known to be highly basic (Jenkins 2007), and combined with the large amount of water from firefighting efforts and rainfall, undoubtedly produced aqueous base throughout the pile.

It is important to understand that 1,3-DPP would not have been directly released from the silica microstructure via the route of aqueous base. It would have been the hydroxyl derivative, $p$-(3-phenylpropyl)phenol, abbreviated as HODPP, that was first released in this manner.

$\cong \mathrm{Si}-\mathrm{O}-\mathrm{DPP}+\mathrm{ROH} \rightarrow \cong \mathrm{Si}-\mathrm{OR}+\mathrm{HODPP}$.

But the pores of an energetic nanocomposite are also filled with a mixture of fine aluminum powder, and one or more finely dispersed metal oxides. Therefore, hydrogen gas could have evolved in the following way (as well as by several other reaction mechanisms in the high-temperature environment of GZ combustion).

$2 \mathrm{Al}+6 \mathrm{H}_{2} \mathrm{O} \rightarrow 2 \mathrm{Al}(\mathrm{OH})_{3}+3 \mathrm{H}_{2}$.

Production of 1,3-DPP might then have followed from a metal oxide-catalyzed reaction of $p$-(3-phenylpropyl) phenol with hydrogen. A similar reduction of phenol to benzene, catalyzed by $\mathrm{MoO}_{3}$, has been reported (Woodward and Glover 1948).

$\mathrm{MoO}_{3}+\mathrm{H}_{2} \rightarrow \mathrm{MoO}_{2}+\mathrm{H}_{2} \mathrm{O}$,

$\mathrm{HODPP}+\mathrm{MoO}_{2} \rightarrow 1,3-\mathrm{DPP}+\mathrm{MoO}_{3}$

Other pathways have been proposed for the release of 1,3-DPP, some without the need for preliminary reactions, but experiments are required to confirm these possibilities.

Based on currently released data, maximum detections for 1,3-DPP (at 290 Broadway, $\sim 0.6 \mathrm{~km}$ from GZ) were measured on or about 5th, 13th, and 21 st October. These last two dates are different from the dates suggesting violent, short-lived fires. That would be expected, of course, considering that 1,3-DPP would probably not survive such extreme fire events but would be converted into other products. In early October, however, full-scale clean-up operations had just begun at GZ, and 1,3-DPP might have been released at more locations in the pile, in some cases through physical or chemical means.

As for the effects of heat, the products of the pyrolysis of 1,3-DPP at $375^{\circ} \mathrm{C}$ are styrene and toluene, in equal amounts (Poutsma and Dyer 1982). This can occur directly in the dry composite (Kidder et al. 2005). Additionally, high temperature oxidation of toluene is known to produce benzene (Brezinsky et al. 1984).

The spikes in VOC detection could also be explained as a result of the rapid combustion of typical materials found within a building structure. If energetic nanocomposite materials, buried within the pile at GZ, were somehow ignited on specific dates (Table 1), violent, short-lived, and possibly explosive fires would result. Such fires would have quickly consumed all combustible materials nearby. The combustible materials available, after a month or two of smoldering fires in the pile, might have been more likely to be those that were less likely to have burned completely on earlier dates, like plastics. Later combustion of such plastic materials, in violent but short-lived fires, could explain the spikes in VOCs seen on those dates.

As for Cahill's data, the presence of compounds of sulfur and silicon in the fine PM seems to fit well with this hypothesis. Sulfur is typically an ingredient of aluminothermic materials (e.g. thermate), and silica is often the 
structural base for energetic nanocomposites. Sulfur might have been released, along with very fine silicon compounds and other species related to energetic nanocomposites, through explosions, violent fires, or other physical disturbances in the pile at GZ.

Along these lines, it is noteworthy that the data from EPA and Cahill show that detection of aluminum, iron, and barium, all of which are common ingredients of thermatelike aluminothermic mixtures (Jones 2006), spiked on specific dates. Cahill's data show a very noticeable simultaneous spike for aluminum and iron on 26th October. The EPA data show that, of the 28 days that aluminum was measured in air during 2001, the dates of maximum detection fall on the same dates as that of iron for the top 9 days in each case. Barium shares eight of these top nine daily maxima.

The metals mentioned by Cahill, for which the "anaerobic incineration" mechanism was proposed, might also be explained by further development of this hypothesis. For example, vanadium oxide has been used in energetic nanocomposites (Gash et al. 2000) and has been added to hybrid aerogels for the improvement of electrical conductivity, and to silica nanocomposites for the purpose of catalysis (Harreld et al. 1998; Luco et al. 1995). The EPA data show a maximum detection for vanadium on 19th December, the same date as EPA's maximum detection of iron, and the date of the second highest detection of both barium and aluminum. The highest detection of barium occurred on 7th March, 2002.

Titanium and nickel, other metals detected in unusual quantities by Cahill, have been used in the production of energetic nanocomposites as well (Gash et al. 2003). Neither EPA nor Cahill reported specific measurements for titanium, but spikes in the detection of nickel are clear in the EPA data on 11th October, 19th December, and 7th March, 2002.

Further testing of this hypothesis, for the presence of energetic materials at GZ, might focus on dust samples. For example, if aluminothermic mixtures were ignited at the WTC, significant quantities of the oxidized aluminum would have been present in the air and dust. Because EPA and Cahill used elemental analyses only, the fraction of aluminum present as aluminum oxide was not identified. Unfortunately, air samples are not likely to be useful at this late date but specific measurement of aluminum oxide in dust samples can certainly be done. Such measurements may also help to explain other anomalies observed at the WTC, such as the plumes of white ash accompanying very bright flames at the South Tower just before its fall (Jones et al. 2008b). Other tests for the remnants of energetic nanocomposites in the WTC dust would be indicative as well.

\section{Conclusion}

The presence of energetic materials, specifically energetic nanocomposites, at GZ, has the potential to explain much of the unusual environmental data seen at the WTC. Thermite, discussed briefly above, is such a pyrotechnic mixture that cannot be easily extinguished and is a common component of energetic nanocomposites. Unusually high detections of sulfur, silicon, aluminum, copper, nickel, iron, barium, and vanadium might all be explained by physical release of materials from such energetic nanocomposites. Additionally, the detection of 1,3-DPP at the WTC supports this hypothesis. Finally, the spikes in VOCs, detected by EPA on specific dates, are more readily explained as a result of short-lived, violent fires caused by energetic materials.

Open Access This article is distributed under the terms of the Creative Commons Attribution Noncommercial License which permits any noncommercial use, distribution, and reproduction in any medium, provided the original author(s) and source are credited.

\section{References}

American Scientist (2003) Researchers present findings on ground zero chemical fire, 16 September 2003, 1:20. http://www.american scientist.org/template/Newsletter?memberid=null\&issueid=1581. Accessed 16 Feb 2008

Boettner EA, Ball GA, Weiss B (1973) Combustion products from the incineration of plastics, University of Michigan, Report No. EPA670/2-73-079, National Technical Information Service, 90-93. http://deepblue.lib.umich.edu/dspace/bitstream/2027.42/3702/5/ anh0435.0001.001.pdf. Accessed 16 Feb 2008

Brezinsky K, Litzinger TA, Glassman I (1984) The high temperature oxidation of the methyl side chain of toluene. Int $\mathrm{J}$ Chem Kinet 16(9):1053-1074. doi:10.1002/kin.550160902

Cahill TA, Shackelford CJ, Meier M et al (2003) Very fine aerosols from the World Trade Center collapse piles: anaerobic incineration. http://e-reports-ext.llnl.gov/pdf/305393.pdf. Accessed 16 Feb 2008

Cahill TA, Cliff SS, Perry KD et al (2004) Analysis of aerosols from the World Trade Center collapse site, New York, October 2-30, 2001. Aerosol Sci Tech 38:165-183. http://www.informaworld.com/ $\mathrm{smpp} / \mathrm{section}$ ?content $=\mathrm{a} 714044206 \&$ fulltext $=713240928$. Accessed 16 Feb 2008

Clapsaddle BJ, Gash AE, Plantier KB et al (2004) Synthesis and characterization of mixed metal oxide nanocomposite energetic materials, LLNL UCRL-PROC-204118. Proceedings of the 31st international pyrotechnics seminar, May 12, 2004. http://ereports-ext.1lnl.gov/pdf/307362.pdf. Accessed 16 Feb 2008

Clapsaddle BJ, Zhao L, Prentice D et al (2005) Formulation and performance of novel energetic nanocomposites and gas generators prepared by sol-gel methods, LLNL UCRL-PROC210871. http://e-reports-ext.1lnl.gov/pdf/318263.pdf. Accessed 16 Feb 2008

Crebellia R, Tomeib F, Zijnoa A et al (2001) Exposure to benzene in urban workers: environmental and biological monitoring of traffic police in Rome. Occup Environ Med 58:165-171. doi: 10.1136/oem.58.3.165 
Dalton L (2003) Chemical analysis of a disaster. Chem Eng News 81(42):26-30. http://pubs.acs.org/cen/NCW/8142aerosols.html. Accessed 16 Feb 2008

ENS (Environment News Service) (2002) Registry to track people exposed to WTC collapse, 18 July 2002. http://www.ensnewswire.com/ens/jul2002/2002-07-18-02.asp

EPA (2002) World Trade Center disaster response air monitoring data summaries, 4 June 2002. http://www.epa.gov/wtc/summaries/ datasummaries.pdf. Accessed 16 Feb 2008

EPA (2004) WTC response, environmental monitoring data, version 3.0, February 2004. The FOIA obtained data was provided on $\mathrm{CD}$, with comma separated value (CSV) files and a query tool. The $\mathrm{CD}$ can be requested through EPA Region II. http://oaspub.epa.gov/nyr/cd. Some of this data is available via downloadable zip files at EPA's website. http://www.epa.gov/ wtc/monitoring/. Accessed 16 Feb 2008

EPA (2006) Environmental information management system, EIMS metadata report-document entry ID: 62021. http://oas pub.epa.gov/eims/xmlreport.display?deid=62021\&z_chk $=65088$. Accessed 16 Feb 2008

Garrett L (2003) Full effects of WTC pollution may never be known. Newsday, 14 September 2003. http://www.newsday.com/news/ health/ny-hsair0911,0,471193.story?coll=ny-homepage-right-area. Accessed 16 Feb 2008

Gash AE, Simpson RL, Tillitson TM et al (2000) Making nanostructured pyrotechnics in a Beaker, Lawrence Livermore National Laboratory (LLNL) UCRL-JC-137593. http://e-reports-ext.1lnl. gov/pdf/247064.pdf. Accessed 16 Feb 2008

Gash AE, Simpson RL, Satcher JH (2002) Energetic nanocomposites with sol-gel chemistry: synthesis, safety, and characterization, LLNL UCRL-JC-146739. http://e-reports-ext.1lnl.gov/pdf/244 137.pdf. Accessed 16 Feb 2008

Gash A, Barbee T, Simpson R et al (2003) Environmentally benign stab detonators, LLNL report UCRL-TR-201628. http://ereports-ext.1lnl.gov/pdf/303520.pdf. Accessed 16 Feb 2008

Gonzalez J (2002) Fallout: the hidden environmental consequences of 9/11, In These Times, 10 September 2002. http://www.alternet. org/911 oneyearlater/14073/?page $=1$. Accessed 16 Feb 2008

Harreld J, Wong HP, Dave BC et al (1998) Synthesis and properties of polypyrrole-vanadium oxide hybrid aerogels. J Non-Cryst Solids 225:319-324. doi:10.1016/S0022-3093(98)00321-4

HHS (US Department of Health and Human Services) (2007) Toxicological profile for benzene. http://www.atsdr.cdc.gov/ toxprofiles/tp3.pdf. Accessed 16 Feb 2008

Jenkins C (2007) Request for an investigation by the Senate Subcommittee on superfund and environmental health into the Falsification of $\mathrm{pH}$ corrosivity data for World Trade Center Dust, J 9/11 studies. http://www.journalof911studies.com/volume/ 200704/DrJenkinsRequestsSenateInvestigationOnWTCdust.pdf

Jones SE (2006) Why indeed did the WTC buildings completely collapse? J 9/11 studies. http://www.journalof911studies.com/volume/200609/ Why_Indeed_Did_the_WTC_Buildings_Completely_Collapse_ Jones_Thermite_World_Trade_Center.pdf. Accessed 16 Feb 2008

Jones SE, Farrer J, Jenkins GS, Legge F et al (2008a) Extremely high temperatures during the World Trade Center destruction, J 9/11 studies. http://www.journalof911studies.com/articles/WTCHigh Temp2.pdf. Accessed 16 Feb 2008

Jones SE, Legge FM, Ryan KR, Szamboti AF, Gourley JR (2008b) Fourteen points of agreement with official government reports on the World Trade Center destruction, The Open Civil Eng J
2(1):35-40. doi:10.2174/1874149500802010035. http://www. bentham-open.org/pages/content.php?TOCIEJ/2008/00000002/ 00000001/35TOCIEJ.SGM

Kidder M, Britt PF, Zhang Z et al (2003) Pore size effects in the pyrolysis of 1,3-Diphenylpropane confined in mesoporous silicas. Chem Commun (Camb) 2003:2804-2805. doi:10.1039/ b310405b

Kidder M, Britt PF, Zhang Z et al (2005) Pyrolysis of mesoporous silica-immobilized 1,3-Diphenylpropane. Impact of pore confinement and size. J Am Chem Soc 127:6353-6360. http://pubs. acs.org/cgi-bin/abstract.cgi/jacsat/2005/127/i17/abs/ja050389w. html. Accessed 16 Feb 2008

Lipton E, Revkin AC (2001) Nation challenged: the firefighters; with water and sweat, fighting the most stubborn fire. New York Times, November 19, 2001

Luco V, MacLachlan DJ, Hook JM et al (1995) Synthesis and characterization of mesostructured vanadium oxide. Chem Mater 7:2220-2223. doi: $10.1021 / \mathrm{cm} 00060 \mathrm{a} 002$

McCaffrey WC, Brues MI, Cooper DG et al (1996) Thermolysis of polyethylene/polystyrene mixtures. J Appl Polym Sci 60:21332140. doi :10.1002/(SICI)1097-4628(19960620)60:12<2133:: AID-APP10>3.0.CO;2-8

Meyerowitz J (2006) Aftermath: World Trade Center archive. Phaldon Publishing, London, p 178. See photograph of the event on 11/08/01 that shows a stunning and immediate change of cloud-like emissions from the pile, from dark smoke to white cloud

MOEE (Canadian Ministry of Environment and Energy) (1997) Internal review of the Ministry of Environment and Energy Response to the Plastimet Fire City of Hamilton July 9-12, 1997, Appendix II (B). http://www.ene.gov.on.ca/envision/techdocs/ 3599e.htm\#chap4. Accessed 16 Feb 2008

Prakash A, McCromick A, Zachariah MR (2004), Aero-sol-gel synthesis of nanoporous iron-oxide particles: a potential oxidizer for nanoenergetic materials. Chem Mater 16(8):1466-1471. http://www. enme.umd.edu/ mrz/pdf_papers/2004_CM_FeO.pdf. Accessed $16 \mathrm{Feb} 2008$

Public Broadcasting Service (PBS) (2002) America rebuilds: a year at ground zero, credited to Great Projects Film Company. http://www. pbs.org/americarebuilds/engineering/engineering_debris_06.html. Accessed 16 Feb 2008

Poutsma ML, Dyer CW (1982) Thermolysis of model compounds for coal. 3. Radical chain decomposition of 1,3-Diphenylpropane and 1,4-Diphenylbutane. J Org Chem 47:4903-4914. doi: 10.1021/jo00146a017

Simpson RL, Satcher JH, Gash AE (2004) Safe and environmentally acceptable sol-gel derived pyrophoric pyrotechnics, LLNL report UCRL-TR-204902. https://e-reports-ext.1lnl.gov/pdf/ 308591.pdf. Accessed 16 Feb 2008

Swartz E, Stockburger L, Vallero D (2003) Polycyclic aromatic hydrocarbons and other semivolatile organic compounds collected in New York City in response to the events of 9/11. Environ Sci Technol 37:3537-3546. http://pubs.acs.org/cgi-bin/ abstract.cgi/esthag/2003/37/i16/abs/es0303561.html. Accessed 16 Feb 2008

Woodward LA, Glover AT (1948) Molybdenum oxide catalysts for the reduction of phenol to benzene. Trans Faraday Soc 44:608616. doi: $10.1039 /$ tf 9484400608

Wright S (2002) Air quality scientists release WTC study. Dateline UC Davis. http://www-dateline.ucdavis.edu/021502/DL_wtc. html. Accessed 16 Feb 2008 